of medical men, and far more rarely order a post-mortem examination, taking other evidence for granted. I cannot conclude without thanking the medical men before mentioned for their valuable coöperation and assistance.

\section{FATAL CASE OF INHALATION OF ROBURITE FUMES.}

By W. A. Hatton, M.B.

IT is a strange coincidence that while a committee was investigating the probable effects of this explosive compound, of which THE LANCET of last week gave so able a summary, a fatal case should bave occurred lately in the Atherton district, the leading features of which will, no doubb, be of interest on account of its very rare occurrence. The deceased, a miner, was at work on Feb. 9 th, and allowing a reasonable time (eight minutes) to elapse after the firing of a roburite shot, proceeded to take down the hanging coal. Ten minutes afterwards be complained of pain in the head and faintness, though he worked till closing time. The next day, when I saw him, he was in a confused condition and complained of a good deal of dizziness and pain, chiefly above the frontal and supra-orbital region; his articulation was thick and almost unintelligible; he was, however, able to give a short account of the whole cceurrence, and attributed the onset of the symptoms to the inhalation of the fumes. There were some nystagmus and indistinctness of vision, owing no doubt to the retinal congestion present. The pulse was thready and irregular, ranging from 70 to 90 in the minute; temperature $101^{\circ}$; there was also marked cyanosis about the lips. The respiration was good, though a little hurried, and there were no abnormal paysical signs on examination of the chest, no cough or odour noticeable in the breath, neither was there anything to lead to a suspicion of any pulmonary congestion. There had been no vomiting or feeling of sickness. The knee jerk was a little exaggerated. The cephalalgia became more intense, coma rapidly supervened, and the patient died on the third day. The post-mortern examination was made, in conjunction with Dr. R. Martin of Atherton, on the 15th; the only noticeable point on external examination was the cyanosis of the lips. On opening the skull the dưra mater was adherent, and found to be inflamed; there was intence venous congestion on the brain surface, and there was some superficial encephalitis present. Punctiform ecchymoses were unusually numerous on section, and very little flaid was present in the lateral ventricles. On opening the thorax, there was no odour perceptible, as has been noticed in cases of nitro-benzine poisoning; the lungs were intensely congested, more so at the apices, though there was no sign of any inflammatory change. The remaining organs were quite healthy, and portions of lung, liver, the stomach, and a kidney were sent to Dr. Paul for especilal examination, though with negative results. There was no trace of carbon monoxide in the blood, tested by the spectroscope, or of the presence of any nitro-benzine componnds. In the report drawn up by Professor Dixon and Messrs. Mounsey and Hannah in the Park-lane Colliery dispute, in relation to the probable effects of the use of roburite, the presence and smell of nitro-benzine were detected in the fumes. On the other hand, at a meeting of the Manchester Geological Society the fumes were stated to be nothing but carbon dioxide and nitrogen; and the joint commission appointed by the workers and owners of the Durbam collieries declared that there was no trace of nitro.benzine found in their experiments.

Walkden.

INTER-PARTUM HOUR-GLASS CONTRACTION. By H. Martyn Eames, L.R.C.P. \& S. ED., L.F.P.S.GLas.

THe following case of inter-partum hour glass contraction seems to me to be of sufficient rarity and interest to warrant its publication.

On Sunday, Jan. 3lst, I was called to a young multiparous woman in labour, whom I had delivered with forceps eleven months previously. On examination I found the os uteri fully dilated, and the uterine contractions strong and regular. I therefore ruptured the membranes, which resulted in the rapid descent of the head to the perineum.
After this the pains gradually, as in her last labour, became inefficien 0 and unsatistactory; so I applied the forceps, and her delivery was effected without any diffisulty, and in about a quarter of an hour a placenta, was expelled. Having discovered it to be a case of twins, I examined for the prirpose of ascerbaining the presentation of the other child, when I found that the liquor amnii had escaped, and the lefb arm was presenting. I therefore determined, if practicable, to turn and deliver without delay; but upon introducing my hand into the uterus I found the internal os uteri intensely constricted, rigidly unyielding, and tenaciously gripping the upper region of the presenting arm, rendering it impossible for me to pass even one finger bey ond the barrier into the upper uterine segment. There being no special indication on the part of the mother for immeduate delivery, I determined to await the effect of forty grains of chloral bydrate in two doses of half an hour's interval. On re-examination I found that the internal os had slightly relaxed, and that the funis bad descended, and was being compressed by the contracted ring, the pulsation being only slightly appreciable. How. ever, I was able to return the prolapsed cord, but fotal turning was out of the question, as I was unable to paes more than a couple of fingers through the constriction. In the interests of the child, as indicated by the almost pulseless cord, I placed the patient deeply under chloroform for the purpose of prompt delivery, by turning if possible. Despite this the obstruction only yielded very slightly, and as I found the funis had ceased to pulsate, and there being no maternal indications for immediate delivery, I decided to leave matters alone for 2 while. In an hour or so I was summoned to my patient, when I found the contraction obliterated, uterine action regular and efficient, the arm obtruding from the vagina and the shoulder had descended into the pelvis. I again administered chloroform, turned and completed the delivesy without any farther trouble. The hand and arm of the child were deeply cyanosed, much swollen, and a deep sulcus remained on the upper arm at the point where it was gripped, thus proving the intensity and persistency of the spasm. I have referred to several authorities, who only describe cases of ante- and postpartum hour-glass contraction, and hence I presume that hour-glass contraction alter the birth of the first child in cases of twins is of very rare occurrence, and it suggests itself to me that it may not be inaccurately defined as inter-partum hour.glass contraction.

Goole, Yorks.

\section{A 9 ithirror}

\section{HOSPITAL PRACTICE BRITISH AND FOREIGN.}

Nulla autem est alia pro certo noscendi via, nisi quamplurimas et mor. borum et dissectionum historias, tum aliorum tum proprias collectas habere, et inter se comparare-MorgagN De Sed. et Caus. Morb., lib. iv. Procemium.

\section{ST. BARTHOLOMEW'S HOSPITAL.}

ACUTE YELLOW ATROPHY OF LIVER; NECROPSY.

(Under the care of Sir DYCE DUCKWORTH.)

THIs case is recorded as it appears wortby of notice, first, on account of the rarity of the disease, and, secondly, becanse it differs in some respects from most other published cases. As in many older cases, the jaundice followed a mental shock. With the onset of coma physical signs pointed to rapid diminution in the size of the liver. 'This probably cannot wholly be accounted for' by the shrinking of the liver, but must be partly due to some change of its position-falling away from the ribs. Instead of the urine, as was supposed usually to be the case, being not very deeply bile-stained, albuminous, and with diminution of salts and urea, the excretion in this case was exceedingly deeply bile-stained, not albuminous, and con tained a fair anount of salts and urea. The urea, how. ever, in this case was only estimated by the nitrogen method, which, like Liebig's method, is open to error. The nearly complete absence of any hæumorrhage throughout the case is noteworthy. For the account 